\title{
Modelling of Wind Pressure Coefficients on C-Shaped Building Models
}

\author{
Monalisa Mallick $\left(\mathbb{D},{ }^{1}\right.$ Abinash Mohanta $\mathbb{D}^{1},{ }^{1}$ Awadhesh Kumar $\mathbb{D}^{2}$ and Vivek Raj $\mathbb{D}^{3}$ \\ ${ }^{1}$ PhD Scholar, Department of Civil Engineering, National Institute of Technology Rourkela, Odisha, India \\ ${ }^{2}$ Professor, Department of Civil Engineering, National Institute of Technology Rourkela, Odisha, India \\ ${ }^{3} M$ Tech Scholar, Department of Civil Engineering, National Institute of Technology Rourkela, Odisha, India \\ Correspondence should be addressed to Monalisa Mallick; monalisa.nitrkl@gmail.com
}

Received 22 August 2018; Accepted 8 November 2018; Published 2 December 2018

Academic Editor: Aiguo Song

Copyright (C) 2018 Monalisa Mallick et al. This is an open access article distributed under the Creative Commons Attribution License, which permits unrestricted use, distribution, and reproduction in any medium, provided the original work is properly cited.

\begin{abstract}
Designs of buildings are changing with emerging demands of several aesthetical features and efficient design based on geometry. Development of new building materials and construction techniques have enabled us to build new buildings which are tall and unsymmetrical, but unfortunately such structures are more susceptible to wind loads. Thus it becomes necessary to estimate wind loads with higher degree of confidence. Although ample information regarding wind load on symmetrical and regular structure is available in various international codes, they lack the study of effect of wind forces on unsymmetrical structures. This paper presents experimental and numerical studies of the wind effect on commonly used C-shaped buildings with varying aspect ratio and its optimization caused by the alteration of angle of incidence. Furthermore, results obtained by numerical analysis have been validated with the experimental one. For this study, numerical analysis has been carried out using ANSYS Fluent with $k-\varepsilon$ model of turbulence. Computational fluid dynamics (CFD) techniques is used to evaluate the surface pressure on various faces of the model for angle of attack of $0^{\circ}$ to $180^{\circ}$ at an interval of $30^{\circ}$ in a subsonic open circuit wind tunnel. The results found by CFD technique are well compared with the experimental results which suggest the feasibility of using this technique of predicting wind pressures on building efficiently and accurately.
\end{abstract}

\section{Introduction}

Gradual increase of demand of tall and unsymmetrical buildings with efficient geometric design and planning needs futuristic visionary and scientific estimates of various kinds of forces. Wind force is one of them, which plays a crucial role in case of unsymmetrical buildings. Shortage of land and demand of good aesthetical view have forced us to construct nonconventional plan-shaped building. Although ample information regarding wind load on symmetrical structure (conventional plan-shaped structure) is available in various international codes, for example, IS: 875 (Part 3): 1987(code of practice for wind loads for buildings and structures) [1], no such direct reference is available for irregular planshaped structures. The effect is even more critical for unsymmetrical and tall structures due to dynamic response arising from vortex shedding and galloping. Among the loads which act on buildings, the wind load is quite difficult to predict. However, the evolution of computer programs for structural analysis has made the prediction of wind pressure relatively easy to design a building to suit any given set of applied loads.

Though now a days nonconventional plan shapes are very common building configurations, experimental as well as numerical data for such shapes for different wind directions are very limited. Various literatures provide the study of effect of wind pressure on tall and irregular shape of buildings. Paterson and Apelt [2] first presented the research on computation of wind flows over threedimensional buildings by numerical analysis and found accurate results for some wind flows over simple threedimensional buildings. Kwok [3] conducted the wind 
tunnel model test to analyse the effect of building shape on the wind-induced response of a tall building with a rectangular cross section. Afterwards, Stathopoulos and Zhou [4] presented the paper which shows the numerical prediction of turbulent wind pressures on the building surfaces with sharp corners of right angles for different wind incidence angle. Miyashita et al. [5] presented effects of corner cuts and openings in high-rise square buildings. $\mathrm{Li}$ et al. [6] have described the results obtained from the measurements of wind effects on two high-rise buildings with 70 storeys and 30 storeys, respectively. Gomes et al. [7] investigated pressure distributions on L-type and U-type building models under varying wind incidence angle. Chakraborty et al. [8] showed that pressure induced on a "+" plan-shaped tall building is widely different from that of a square plan-shaped tall building. Amin and Ahuja [9] presented the effects of side ratio on wind pressure distribution on rectangular buildings. Dagnew et al. [10] focused on numerical analysis of wind pressures on high-rise buildings by using the Commonwealth Advisory Aeronautical Council (CAARC) building model. The authors applied CFD techniques to predict wind load on CAARC irregular-shaped model. Chakraborty et al. [11] presented a study that showed irregular plan-shaped buildings are subjected to different pressure distributions, as compared to regular plan-shaped buildings after distribution. Yi and Li [12] conducted experiment in a tall building at Hong Kong as well as wind tunnel model test to explain force and pressure coefficients and high-frequency balance. The wind tunnel test result was seen to be fairly equivalent with a full model test. Li et al. [13] also conducted the wind tunnel test on L-plan-shaped tall building to quantify dynamic load across the wind. They proposed an empirical formulation by considering the side ratio and territory of the building to express wind load. Bhattacharyya and Dalui [14] investigated mean wind pressures on E-plan-shaped tall building and compared experimental results with numerical analysis using CFD. They compared their results by plotting pressure contours on all the surfaces using experimental as well as predicted values using CFD analysis. For better comparison of the results, the Fourier series expansion was obtained using the experimental data and compared with both the experimental data and CFD analysis. Li et al. [15] studied some recent efforts for credible computational fluid dynamics simulations in China. Chow et al. [16] investigated to simulate smoke filling in big halls by CFD. Mohanta and Patra [17] used CFD simulation for studying the flow field distribution in converging compound channel by the LES turbulence model.

In present study, numerical as well as experimental analysis has been carried out on irregular shape, i.e., Cshaped of the building for wind incidence angle of $0^{\circ}$ to $180^{\circ}$ at the interval of $30^{\circ}$. ANSYS FLUENT is used to numerically model the domain and study the wind flow, and experimental data were obtained by using wind tunnel. The main purpose of this paper is to assess the change in wind pressure on different faces of $\mathrm{C}$-shaped model due to change in wind angle and aspect ratio (height) of the building by experimental analysis and numerical analysis, and then those results were validated. Validation of results is necessary because there is no such direct reference from where wind pressure on the irregular shape of the building could be calculated. So, it becomes necessary to compare the experimental and numerical data.

\section{Experimental Setup}

2.1. Details of Experiments and Models. Experiments are carried out in an open circuit subsonic wind tunnel in the Aerodynamics Laboratory of the Department of Aerospace Engineering, Indian Institute of Technology Kharagpur, India. The wind speed is kept constant at $12.9 \mathrm{~m} / \mathrm{s}$. The wind tunnel with a bottom surface made up of plywood, a test section is $1.83 \mathrm{~m}$ long, and cross-sectional dimensions of $0.61 \mathrm{~m} \times 0.61 \mathrm{~m}$. Models are placed within the boundary layer zone, centrally in the test section at a distance of $1.2 \mathrm{~m}$ from the beginning of the test section. To ascertain models within the boundary layer zone, wooden cubic blocks of $25 \mathrm{~mm}$ size, and clear spacing of $50 \mathrm{~mm}$ in all directions are fixed on a $4 \mathrm{~mm}$ thick plywood sheet as shown in Figure 1.

The experimental models are made of transparent Perspex sheet of $3 \mathrm{~mm}$ thickness. Details of the two C-shaped models, as C-1 and C- 2 of varying height ratios configurations, are shown in Figures 2(a)-2(c) and given in Table 1. Figure 3 represents the photograph of the C-shaped building model placed in the test section.

The models are fitted with 90 to 120 numbers of pressure-tapping points in 4-5 rows and 3-5 columns on the surfaces. The pressure-tapping points are kept at less spacing near the wall boundaries to tap the sharp pressure variation due to flow separation and at larger spacing in the middle of the surfaces.

Free stream velocity during the experiment is measured with the help of the pitot tube. The models are fitted with 90 to 120 numbers of pressure-tapping points in 4-5 rows and 3-5 columns on the surfaces. The pressure-tapping points are kept at less spacing near the wall boundaries to tap the sharp pressure variation due to flow separation and at a larger spacing in the middle of the surfaces. The free ends of tubes are connected to Digital Sensor Array (DSA) to record the fluctuating wind pressure at the corresponding tapping points. All data are measured by a DSA scan valve corporation, model DSA $3217 / 16$ pox, USA. This DSA device is set to give an average pressure of $5 \mathrm{~s}$ duration. At the same time, for greater accuracy, a pressure measurement at each tapping point is repeated for three times, and the mean of three pressure data are obtained. The pressure coefficient $\left(C_{P}\right)$ for each tapping point is calculated by putting the pressure data in the following equation as follows:

$$
C_{P}=\frac{P-P_{\infty}}{P_{0}-P_{\infty}},
$$

where $p=$ mean pressure data obtained experimentally, $P_{\infty}$ $=$ the static pressure in the reference tube, and $P_{0}=$ total pressure in the settling chamber. 


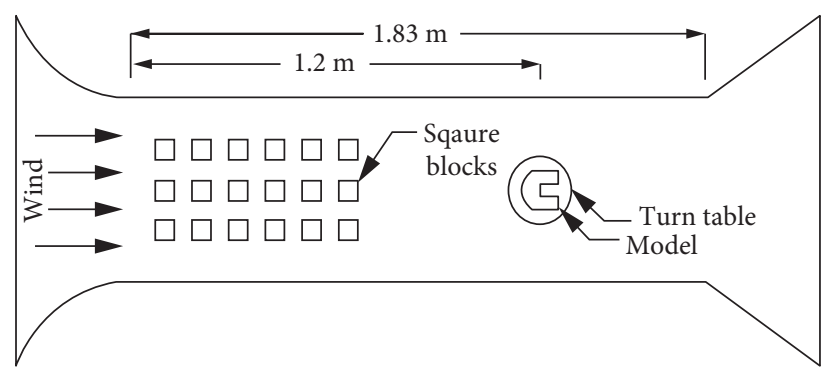

FIgURE 1: The schematic diagram of wind tunnel.

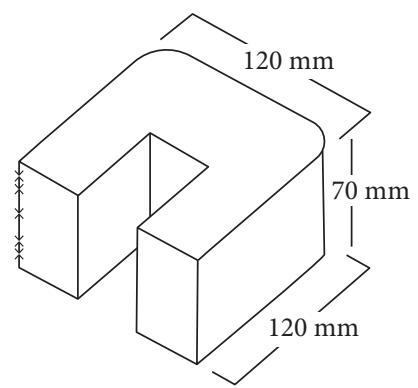

(a)

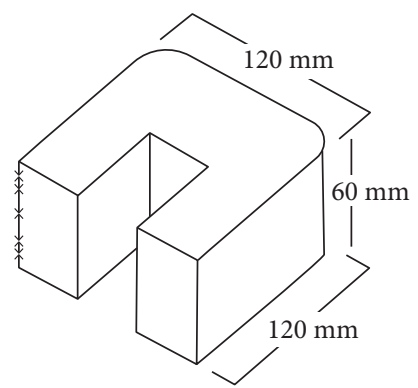

(b)

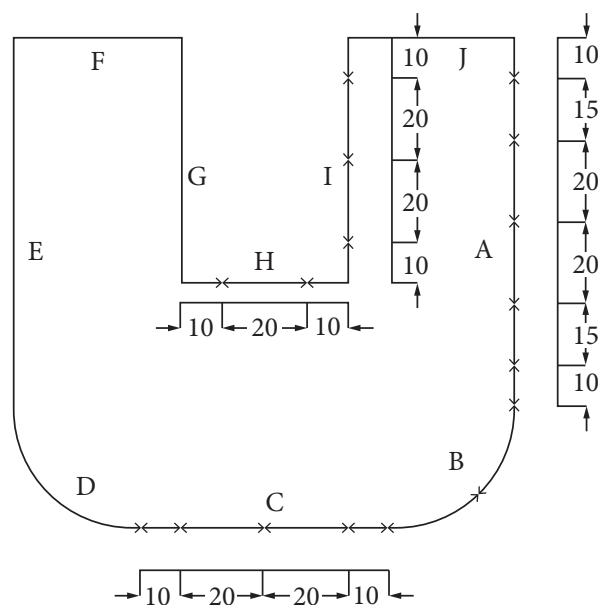

(c)

Figure 2: $(\mathrm{a}-\mathrm{c})$ Isometric view of $\mathrm{C}-1$ - and C-2-shaped building model and pressure-tapping locations along the periphery of models.

TABLE 1: Details of building models with different aspect ratios.

\begin{tabular}{lccccccc}
\hline $\begin{array}{l}\text { Sl. } \\
\text { No. }\end{array}$ & $\begin{array}{c}\text { Overall depth, } D \\
(\mathrm{~mm})\end{array}$ & $\begin{array}{c}\text { Depth, } d \\
(\mathrm{~mm})\end{array}$ & $\begin{array}{c}\text { Overall breadth, } B \\
(\mathrm{~mm})\end{array}$ & $\begin{array}{c}\text { Breadth, } b \\
(\mathrm{~mm})\end{array}$ & $\begin{array}{c}\text { Height, } H \\
(\mathrm{~mm})\end{array}$ & $\begin{array}{c}\text { Plan area, } \\
\left(\mathrm{mm}^{2}\right)\end{array}$ & $\begin{array}{c}\text { Radius of curvature, } R \\
(\mathrm{~mm})\end{array}$ \\
\hline C-1 & $(2)$ & $(3)$ & $(4)$ & $(5)$ & $(6)$ & 70 & $(8)$ \\
C-2 & 120 & 90 & 120 & 60 & 70 & 11613 & 30 \\
\hline
\end{tabular}

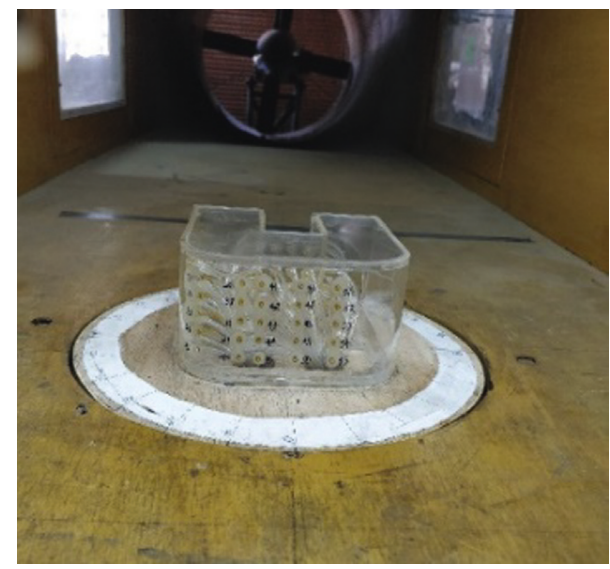

Figure 3: Photograph of C-shaped building model in the test section.

\section{Numerical Modelling}

Numerical simulations have been carried out in this study using ANSYS Fluent using the computational fluid dynamic (CFD) technique, based on the control volume method. The RNG $k-\varepsilon$ model is used to simulate the turbulence effects. The RNG model is developed using renormalization group (RNG) methods to solve the Navier-Stokes equations, to account for the effects of smaller scales of motion. The RNG approach is a mathematical technique that can be used to derive a turbulence model similar to the $k-\varepsilon$ model. Bhattacharyya and Dalui [18] studied wind force and pressure coefficients on the surfaces of an unsymmetrical E-shaped building using CFD ANSYS CFX software. They used two equations $k-\varepsilon$ turbulence model for modelling their works which offers a good compromise between numerical 
effort and computational accuracy. Jena et. al [19] presented numerical studies on the interference effect on pentagonshaped tall buildings and analysis performed with the realizable $k-\varepsilon$ model. Swaddiwudhipong and Khan [20] investigated wind-induced dynamic response of tall buildings using CFD. A comparative study between two widely used turbulence models, i.e., LES and $k-\varepsilon$ Reynolds-average Navier-Stokes models have been made by Cheng et al. [21]. Villalpando et al. [22] studied the flow simulation of turbulence models around a wind turbine NACA 63-415 airfoil at various angles of attack. The RNG (renormalization group) model incorporates modifications over the standard $k$ - $\varepsilon$ [22] model, which improves its performance. Uchida [23] presented a new evaluation technique for wind turbine generators design using a CFD model-based unsteady flow simulation with changes of wind direction.

It is advantageous to use the $(k-\varepsilon)$ turbulence model as most commonly used in computational fluid dynamics (CFD). It simulates mean flow characteristics for turbulent flow conditions. It is a two-equation model which gives a general description of turbulence by means of two transport equations.

(i) The first transported variable determines the energy in the turbulence and is called turbulent kinetic energy $(k)$.

(ii) The second transported variable is the turbulent dissipation $(\varepsilon)$ which determines the rate of dissipation of the turbulent kinetic energy.

The $k-\varepsilon$ turbulence model is limited to the fully developed turbulent and nonseparated flows. It can have stability issues due to numerical stiffness. This model is still used widely despite its disadvantages. This performs poorly for complex flows involving severe pressure gradient, separation, and strong streamline curvature. The RNG produces lower turbulence levels and can underestimate the value of $k$. This produces a less viscous flow that creates more realistic flow features with the complex geometry.

3.1. Numerical Analysis. For numerical analysis, the models of C-shaped buildings of different aspect ratios have been created in ANSYS and then analysed by using the $k-\varepsilon$ model of turbulence. ANSYS (Fluent) uses the finite element method to solve the governing equations, i.e., the region of interest is divided into the finite number of cells (the mesh or grid).

Data considered in numerical analysis:

(i) Types of fluid: air

(ii) Density of air: $1.225 \mathrm{Kg} / \mathrm{m}^{3}$

(iii) Viscosity of air: $1.789 \times 10^{-5} \mathrm{~kg} \cdot \mathrm{s} / \mathrm{m}$

(iv) Turbulence model: $k-\varepsilon$ model

(v) Solver: pressure-based

3.2. Domain and Meshing. The domain size as shown in Figures 4(a) and 4(b) is considered as mentioned in Franke et al. [24]. The upstream side is considered as $5 \mathrm{H}$ from the face of the building, downstream side is taken as $15 \mathrm{H}$ from the face of the building, two side clearance of the domain is taken as $5 \mathrm{H}$ from the face of the building, and top clearance is also taken as $5 \mathrm{H}$ from the top surface of the building. Such large size of the domain helps in vortex generation at the leeward side of the building, and backflow of wind can also be prevented.

The finite volume discretization approach is used to discretize the whole domain so that separation of wind flow, upwash, and downwash mechanisms can happen similar to the experimental study. The discretization (meshing) of the C-shaped model is shown in Figure 5.

3.3. Boundary Conditions. For completing numerical modelling and simulation, there are several boundary conditions which are considered. The flow parameter at inlet, outlet wall, and surface are needed to be considered. At inlet, the velocity of flow is $12.9 \mathrm{~m} / \mathrm{s}$, and the same velocity is provided for experimental procedure so that the result could be compared. The flow velocity at inlet is along the positive $X$ direction.

\section{Results and Discussion}

4.1. Wind Flow Pattern. Pressure variation on the building is directly influenced by wind flow pattern. Vortex generation and different types of mechanism such as separation of flow, upwind, and downwind happen due to dynamic behavior of wind flow. To investigate such mechanisms more accurately, wind flow patterns around the $\mathrm{C}$-shaped building are being studied for different angle of incidences varying from $0^{\circ}$ to $180^{\circ}$ at an interval of $30^{\circ}$ using the CFD technique. Flow pattern for different angles of incidences are shown in Figures 6(a)-6(e).

Wind is directly affecting Face $\mathrm{C}$ for wind incidence angle $0^{\circ}$ to $180^{\circ}$, respectively, so the pressure distribution is symmetrical about vertical axis, and vortices generated at the wake region are also symmetrical for both the cases (Figure 6).

4.2. Variation of Pressure Coefficients. The study of pressure coefficient is necessary in every unconventional-shaped building which is designed under wind excitation. Chakraborty et al. [11] and Mukherjee et al. [25] analysed that the critical pressure coefficients may not be found perpendicular to wind incidence angles only. For this reason, a detailed study on wind pressure variation is required with respect to wind incidence angles.

4.3. Experimental Results. Pressure contour on different faces are plotted for every angle of incidence. Some pressure contours are shown in Figures 7 and 8, respectively, for all the faces. Also, mean pressure coefficients of all the faces are shown in Figures 9(a) and 10(a).

Figures 7 and 8 show the mean pressure coefficient contours on the faces of the model C- 1 and C-2 at wind incidence angles of $0^{\circ}$ to $180^{\circ}$ at an interval of $30^{\circ}$. For wind 


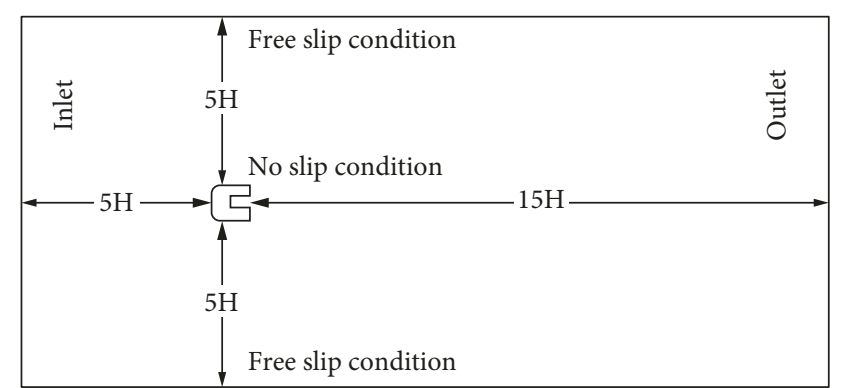

(a)

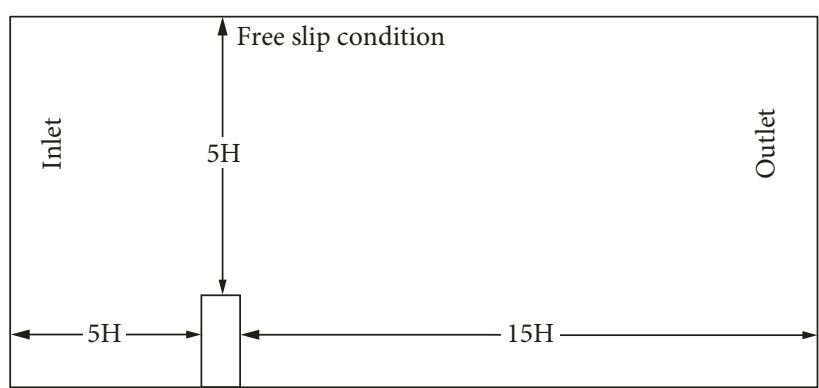

(b)

Figure 4: $(\mathrm{a}, \mathrm{b})$ Domain for the plan and elevation.

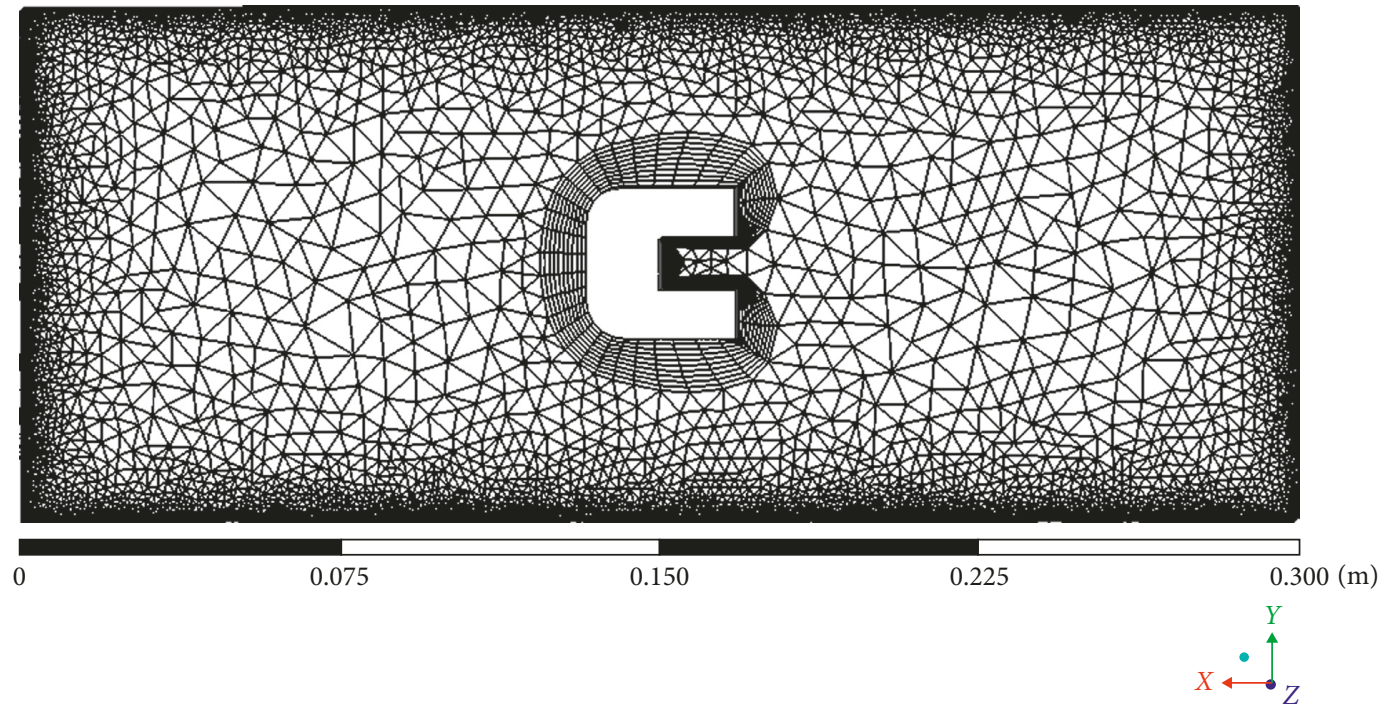

Figure 5: Meshing of C-shaped model.

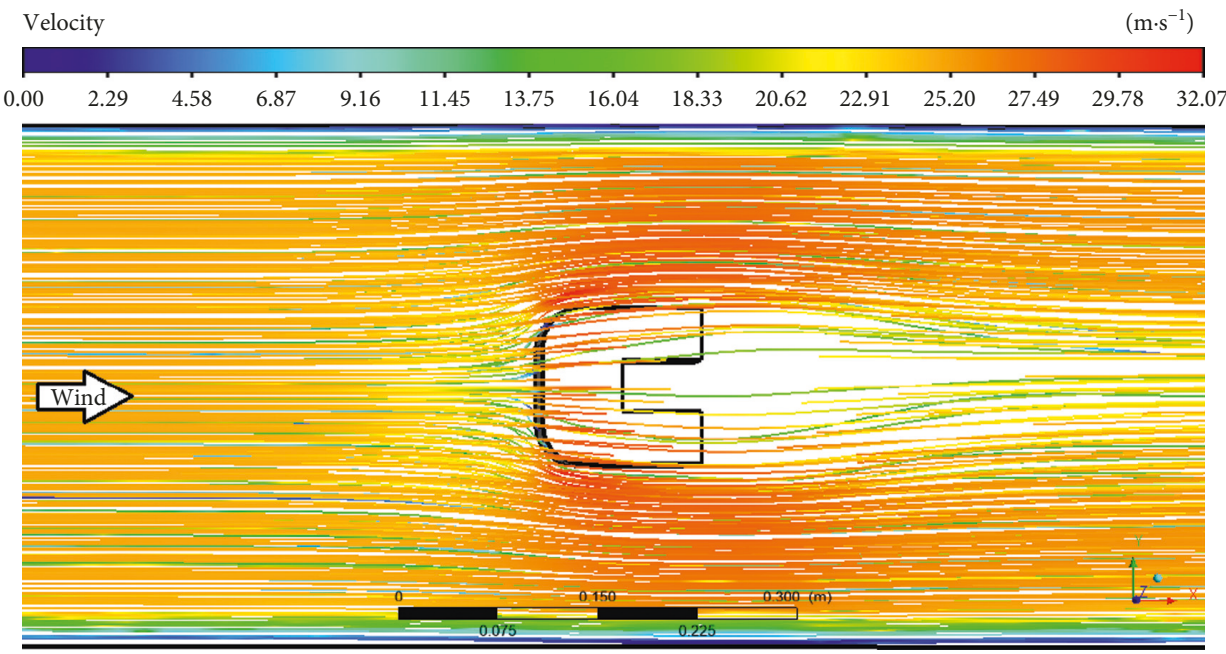

(a)

Figure 6: Continued. 


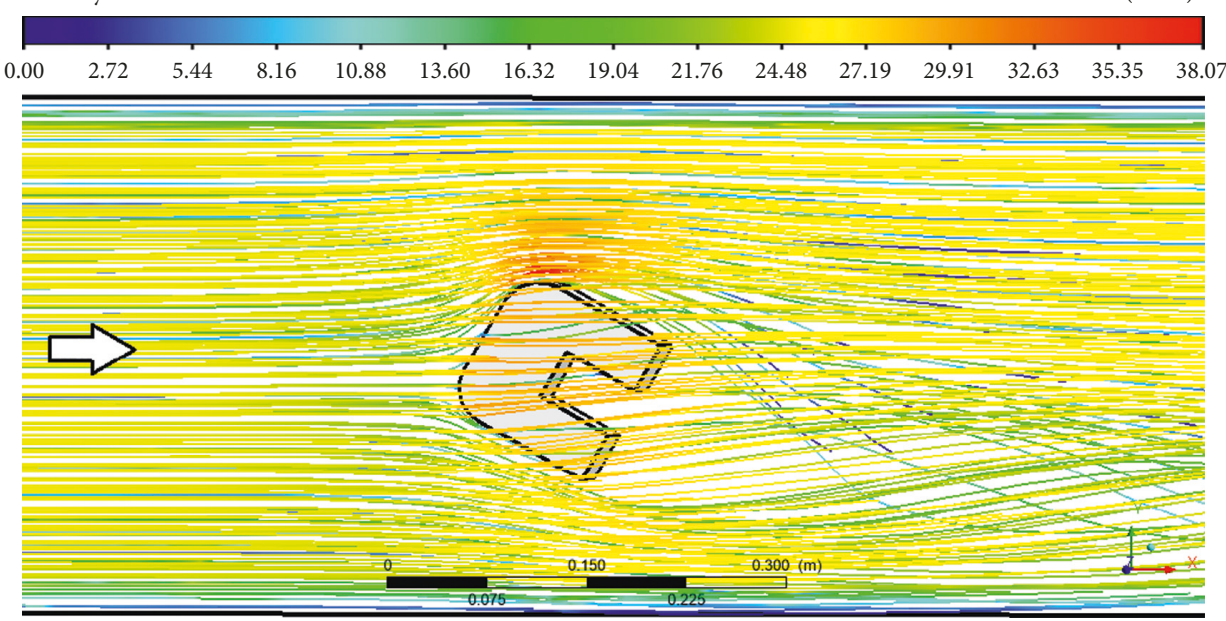

(b)

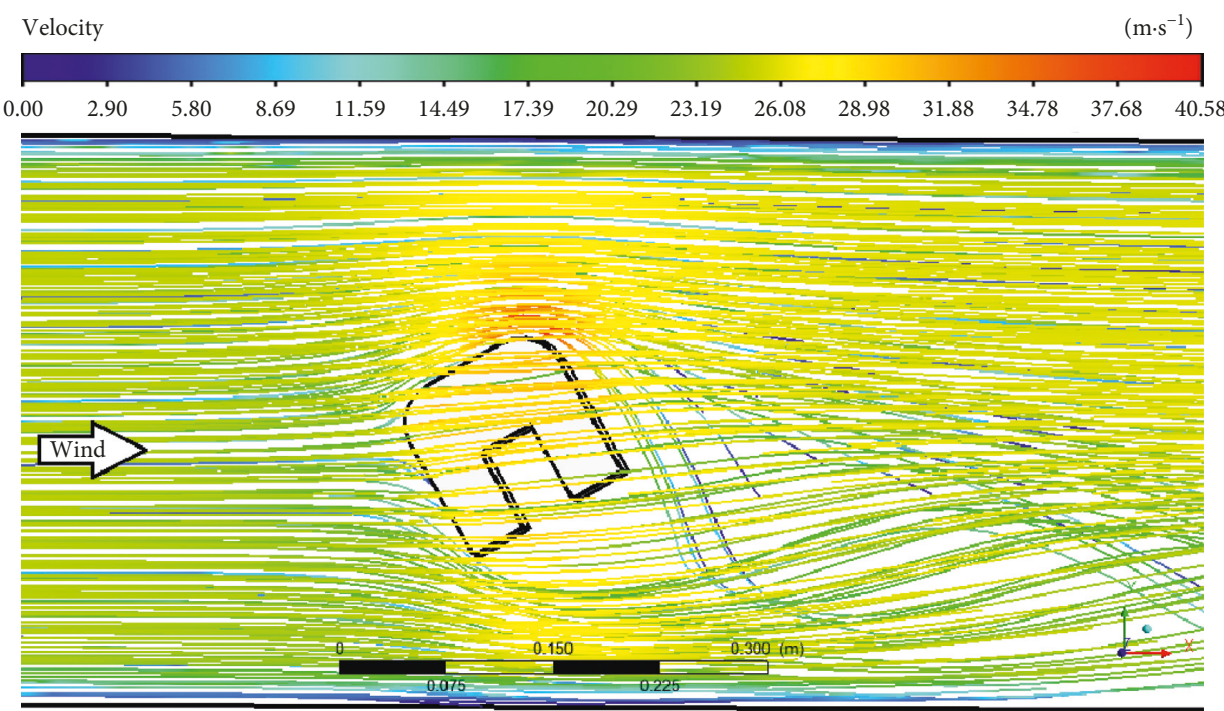

(c)
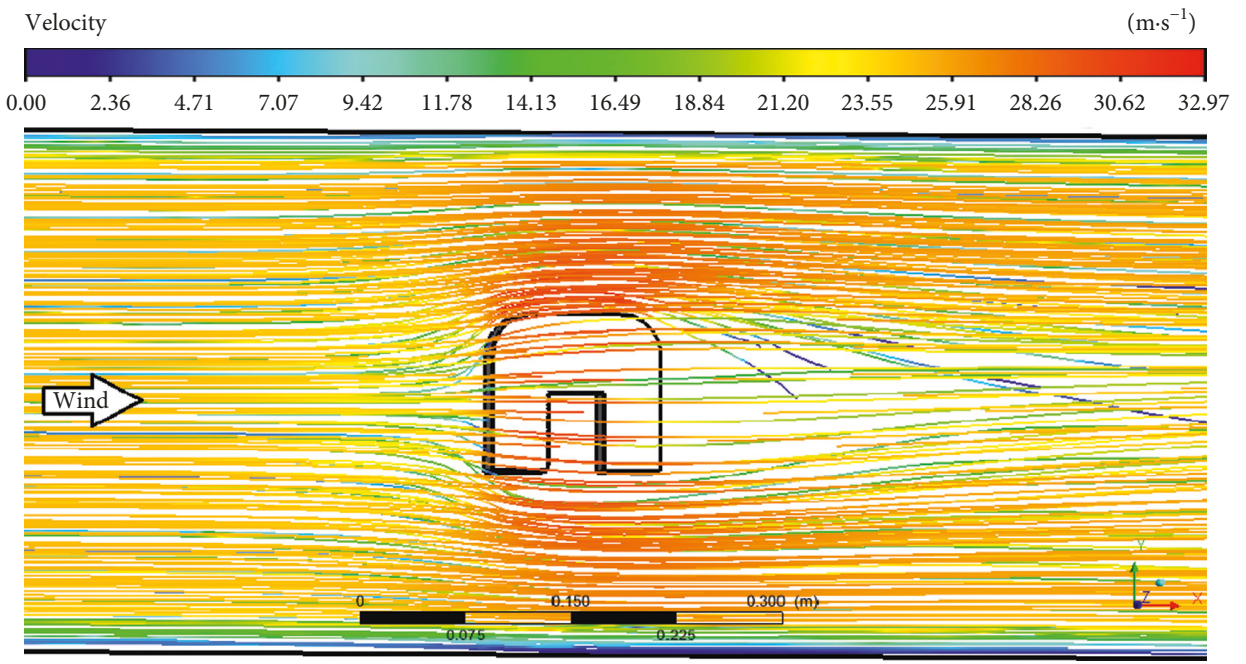

(d)

Figure 6: Continued. 


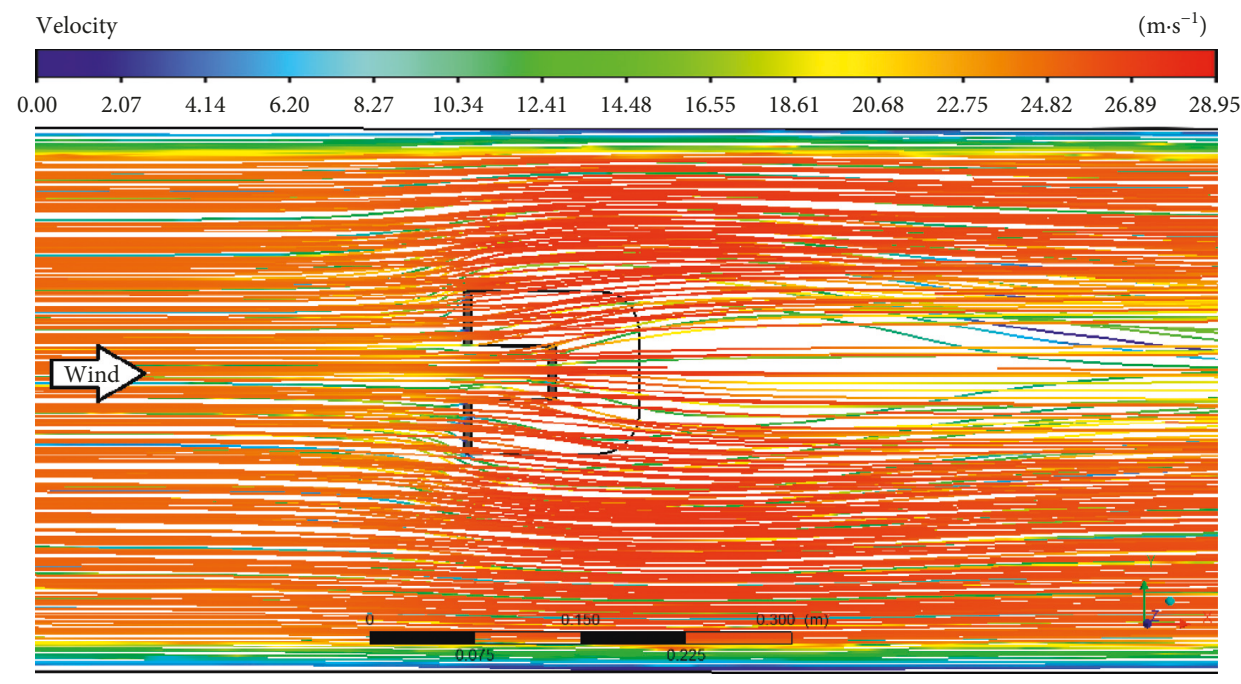

(e)

Figure 6: Wind flow pattern for different wind incidence angles. (a) $0^{\circ}$. (b) $30^{\circ}$. (c) $60^{\circ}$. (d) $90^{\circ}$. (e) $180^{\circ}$.

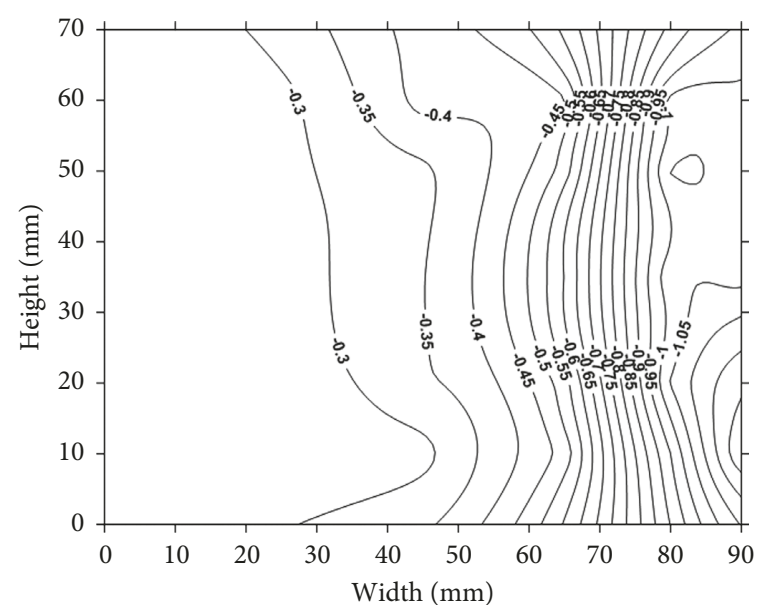

(a)

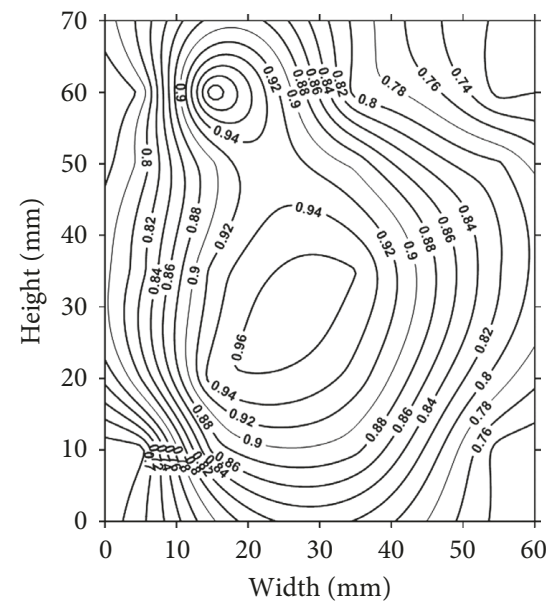

(c)

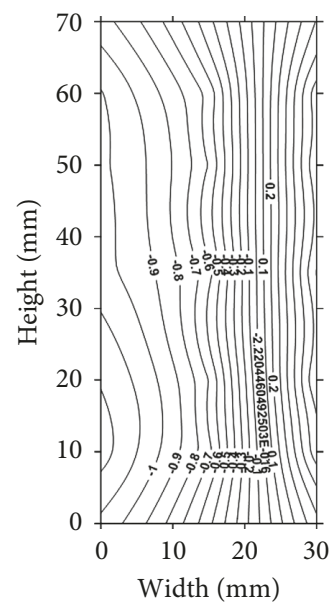

(b)

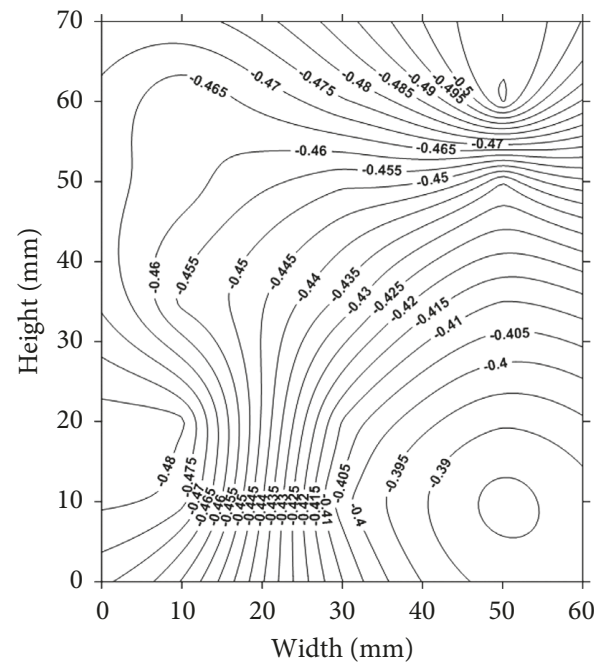

(d)

Figure 7: Continued. 


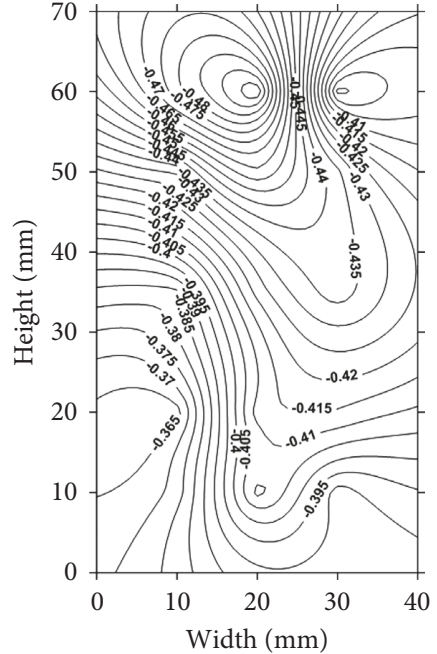

(e)

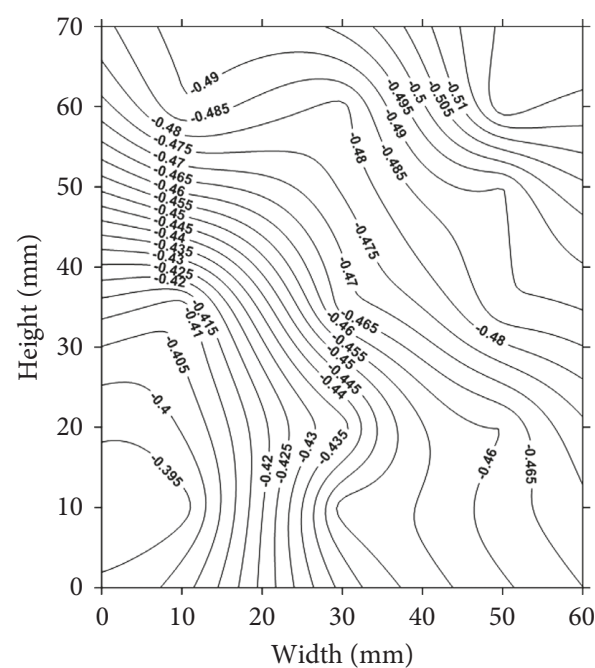

(f)

Figure 7: Pressure contour on different faces of the C-1 model at different wind angles. (a) Face A $90^{\circ}$. (b) Face B $45^{\circ}$. (c) Face C $0^{\circ}$. (d) Face G $90^{\circ}$. (e) Face H $180^{\circ}$. (f) Face I $90^{\circ}$.

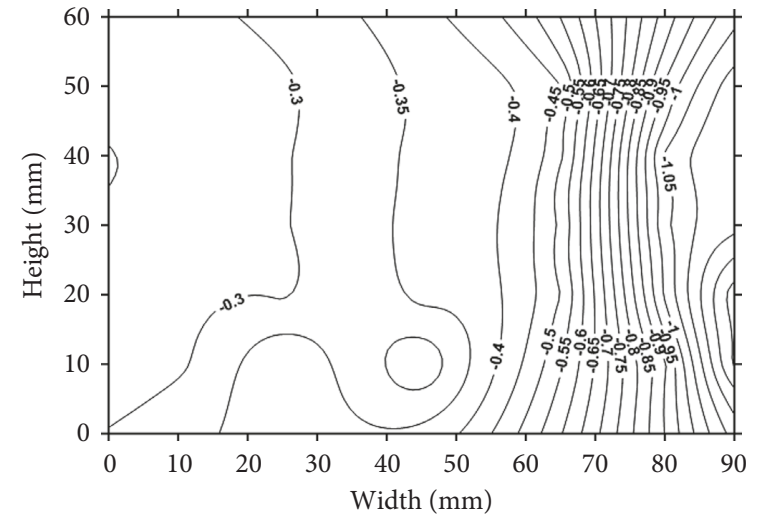

(a)

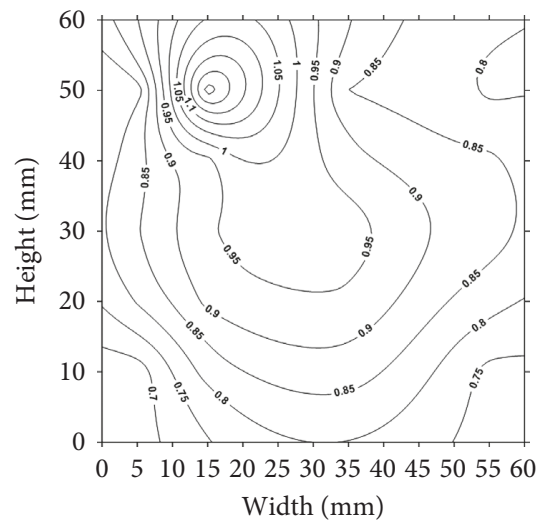

(c)

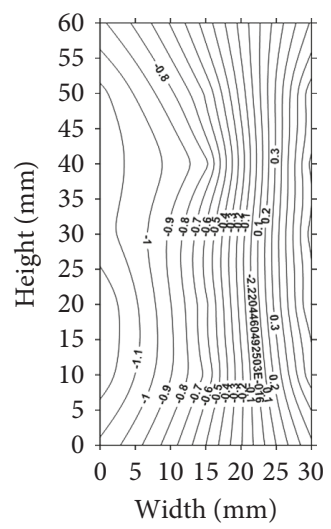

(b)

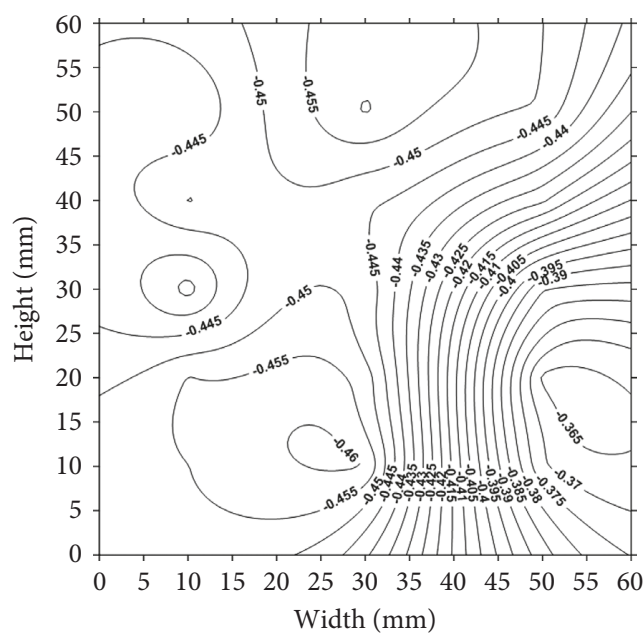

(d)

FIgURe 8: Continued. 


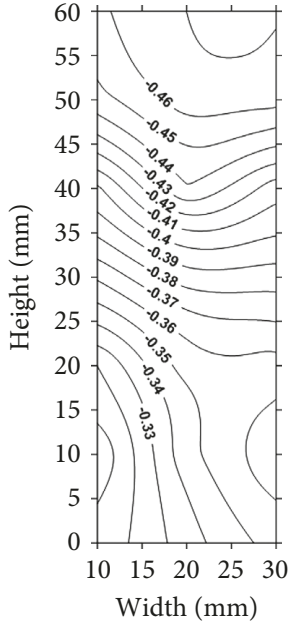

(e)

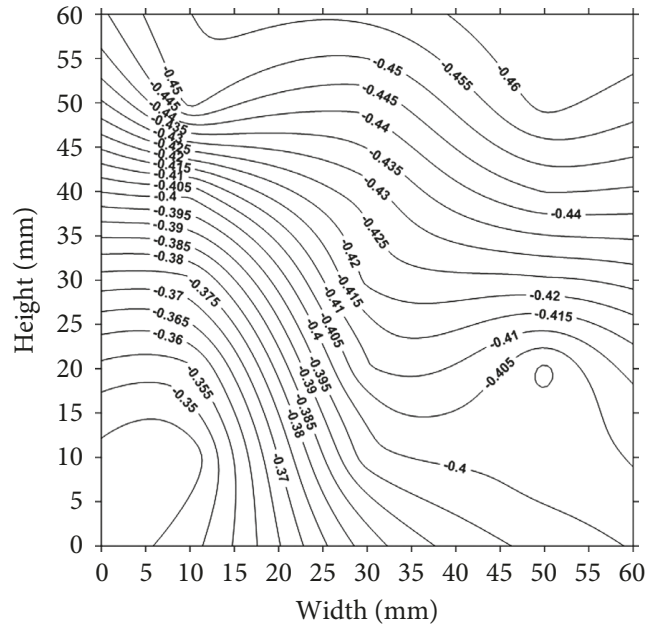

(f)

Figure 8: Pressure contour on different faces of the C-2 model at different wind angles. (a) Face A $90^{\circ}$. (b) Face B $45^{\circ}$. (c) Face C $0^{\circ}$. (d) Face G $90^{\circ}$. (e) Face H $180^{\circ}$. (f) Face I $90^{\circ}$.

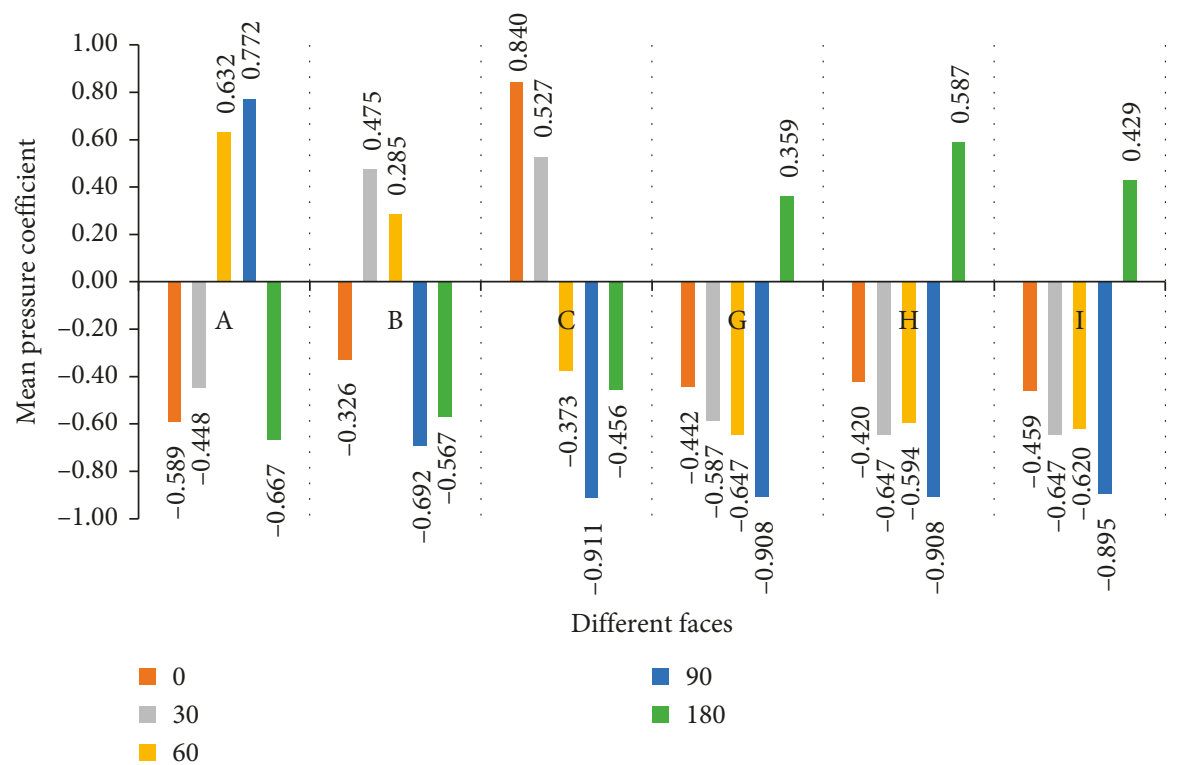

(a)

Figure 9: Continued. 


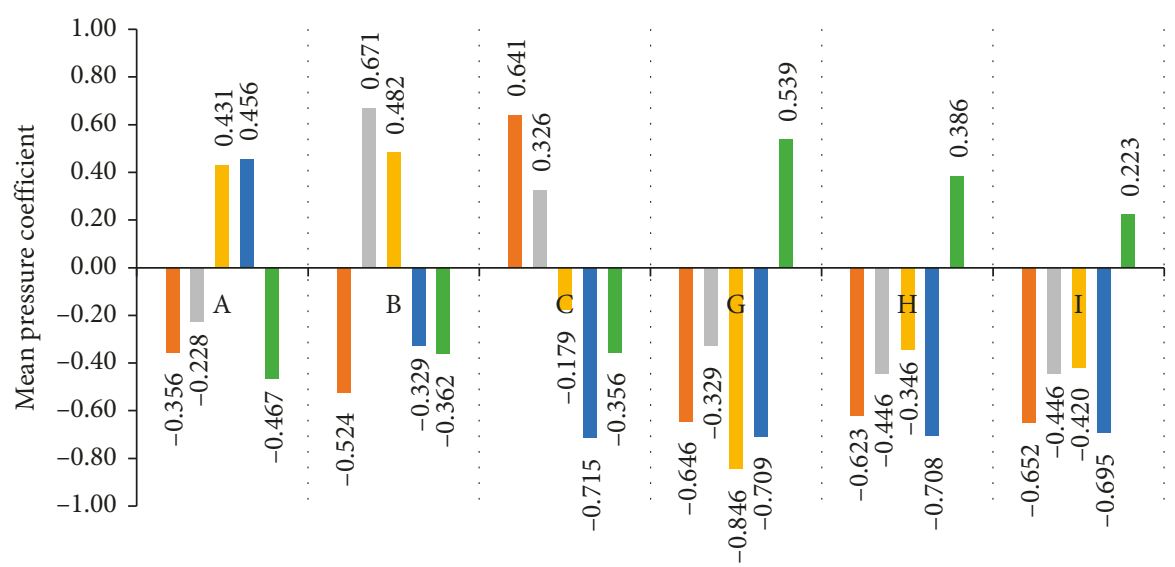

Different faces

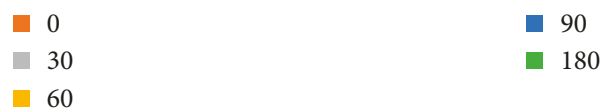

(b)

Figure 9: Mean pressure coefficients for all the faces of the C-1 model. (a) Experimental study. (b) Numerical study.

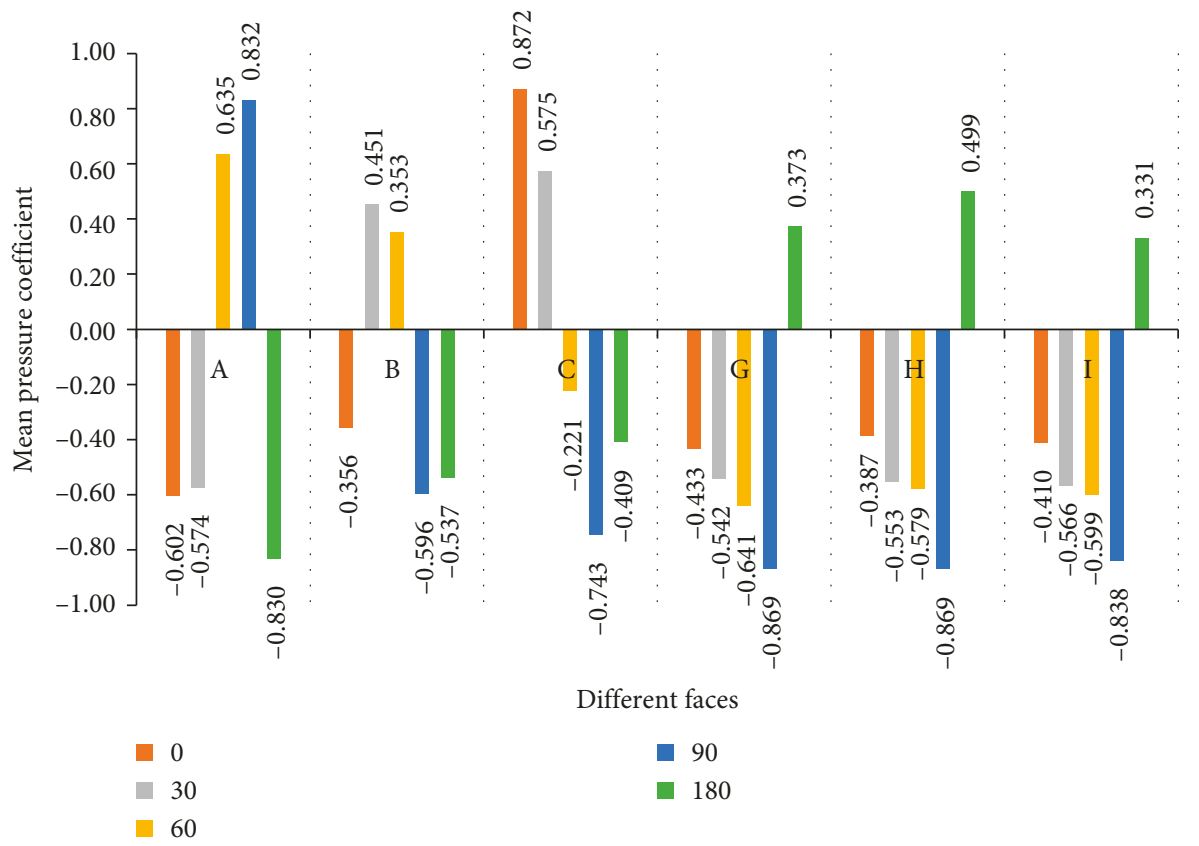

(a)

FIgURE 10: Continued. 


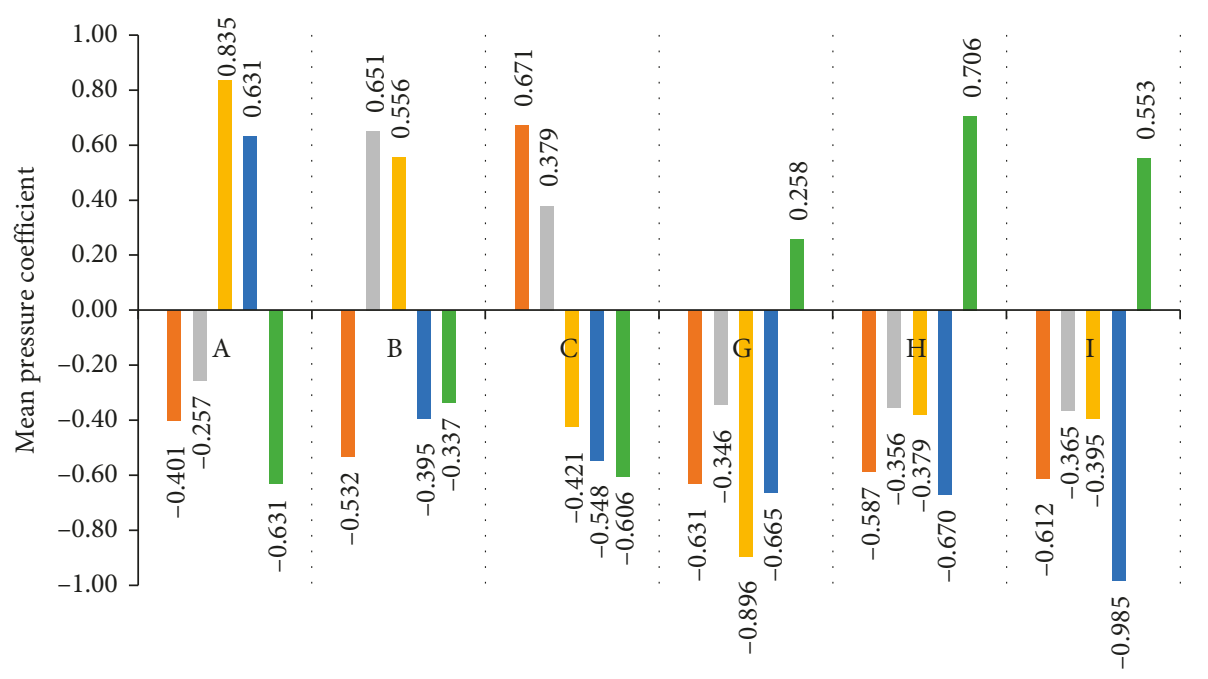

Different faces

$$
\begin{aligned}
& \square \\
& \square \\
& \quad 30 \\
& 60
\end{aligned}
$$

$$
\begin{gathered}
90 \\
-180
\end{gathered}
$$

(b)

Figure 10: Mean pressure coefficients for all the faces of the C-2 model. (a) Experimental study. (b) Numerical study.

incidence angle $0^{\circ}$, Face $\mathrm{A}$ is parallel to the wind flow direction, and the front face of $\mathrm{C}$ is perpendicular to the direction of flow. Faces $\mathrm{G}, \mathrm{H}$, and I are inner windward faces. In Face $\mathrm{A}$, maximum negative $C_{p}$ occurs at the right side and minimum at the left side of the side face in Figure 7(a). Figure $7(\mathrm{~b})$ indicates that the maximum pressure occurs in the left side and minimum in the right side of the curvature portion (Face B) due to flow separation of wind flow. In Figure 7(c), Face $\mathrm{C}$ is perpendicular to the wind flow, and the maximum positive pressure occurs at the central part of the face and minimum pressure at both edge sides due to curvature and edge effect as well. Inner windward Faces G and I have similar flow pattern (Figures 7(d) and 7(e)). Negative pressure decreases towards the edge. Similarly, the mean pressure coefficient contours of the $\mathrm{C}-2$ shaped model are show in Figure 8.

4.4. Numerical Results. Pressure variation and mean pressure coefficients of all the faces of C-1 and C-2 models are also studied numerically in detail by CFD for different wind incidence angles. It can be seen clearly that numerically predicted pressure contours are converged well with the experimentally predicted results. But, very less variation in mean pressure coefficients are observed with respect to the experimental results (Figures 9 and 10).

4.5. Error Analysis. Error analysis is also performed by obtaining mean percentage error (ME), standard deviation (SD), coefficient of determination $\left(R^{2}\right)$, mean absolute error (MAE), root mean square error (RMSE), and mean absolute percentage error (MAPE) [26, 27]. The percentage of mean error for prediction of $C_{p}$ by various models and their

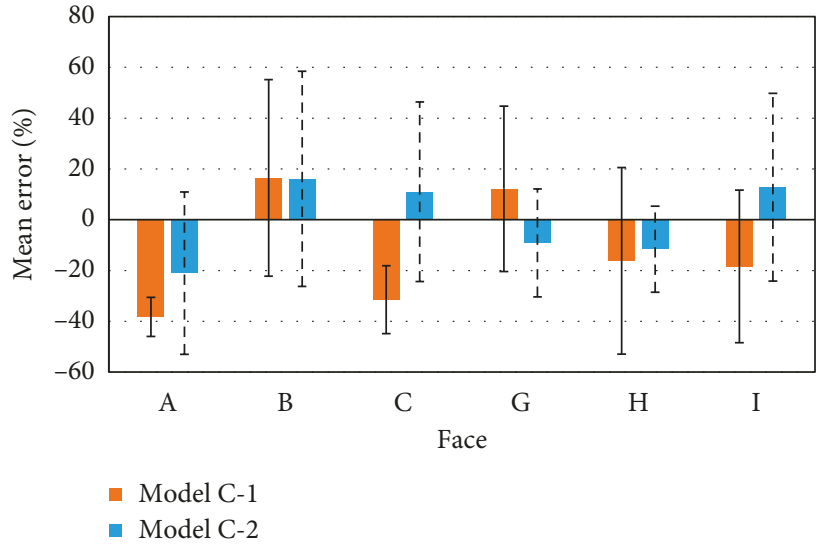

Figure 11: Percentage of mean error for different faces of the building.

TABLe 2: Error analysis of predicted $C_{p}$ for model of C-1.

\begin{tabular}{lcccc}
\hline Face & $R^{2}$ & MAE & RMSE & MAPE \\
\hline A & 0.99 & 0.234 & 0.238 & -9.212 \\
B & 0.86 & 0.232 & 0.241 & -7.812 \\
C & 0.99 & 0.178 & 0.182 & -6.739 \\
G & 0.83 & 0.208 & 0.210 & -18.488 \\
H & 0.87 & 0.211 & 0.212 & -21.818 \\
I & 0.86 & 0.200 & 0.200 & -15.976 \\
\hline
\end{tabular}

standard deviation is shown in Figure 11. Tables 2 and 3 show the error analysis of the present experimental dataset with different faces of C-1 and C-2 models. All the predicted $R^{2}$ values nearly 0.99 which is very good for fitting other data and also the RMSE values are within the permissible limit for 
TABLE 3: Error analysis of predicted $C_{p}$ for model of C-2.

\begin{tabular}{lcccc}
\hline Face & $R^{2}$ & MAE & RMSE & MAPE \\
\hline A & 0.95 & 0.223 & 0.228 & -11.369 \\
B & 0.92 & 0.196 & 0.197 & -3.718 \\
C & 0.95 & 0.198 & 0.198 & -21.524 \\
G & 0.95 & 0.096 & 0.099 & -6.717 \\
H & 0.96 & 0.094 & 0.128 & -14.053 \\
I & 0.89 & 0.195 & 0.197 & -13.872 \\
\hline
\end{tabular}

all the faces. The better results regarding error analysis show the acceptability of the C-shaped model for the practical application.

\section{Conclusions}

The current study shows that pressure induced on the model building is significantly affected by the model geometry, configuration, aspect ratios, and angle of incidence. The significant outcomes of the present study are summarized as follows:

(i) Mean pressure coefficients are the main objective of this study. Maximum positive mean pressure coefficients occur at the front face of $\mathrm{C}$, and maximum negative pressure occurs at the inner face of the model.

(ii) The study has been conducted with a C-shaped model experimentally as well as numerically using the wind tunnel test and CFD technique, respectively.

(iii) Pressure variation on the building is directly influenced by wind flow pattern.

(iv) Vortex generation and different types of mechanism such as separation of flow, upwash, and downwash are happened due to dynamic behavior of wind flow.

(v) The predicted values of the error analysis are measured by four accuracy measurement procedures such as $R^{2}$ value, mean absolute error (MAE), root mean square error (RMSE), and mean absolute percentage error (MAPE). It is observed that all the errors are within the permissible limit.

\section{Data Availability}

The data used to support the findings of this study are available from the corresponding author upon request.

\section{Conflicts of Interest}

The authors declare that they have no conflicts of interest.

\section{Acknowledgments}

The authors express deep sense of gratefulness to Head of the Department of Aerospace Engineering, Indian Institute of Technology Kharagpur, India, for permitting and providing facilities to carry out the experiments. The authors are also thankful to Head of the Department of Civil Engineering, NIT Rourkela, and the National Institute of Technology Rourkela for the support.

\section{References}

[1] IS:875 (Part 3)-1987, Code of Practice for Design Loads for Buildings and Structures, Bureau of Indian Standards (BIS), Manak Bhawan, New Delhi, India, 2003.

[2] D. A. Paterson and C. J. Apelt, "Computation of wind flows over three-dimensional buildings," Journal of Wind Engineering and Industrial Aerodynamics, vol. 24, no. 3, pp. 193-213, 1986.

[3] K. C. S. Kwok, "Effect of building shape on wind-induced response of tall building," Journal of Wind Engineering and Industrial Aerodynamics, vol. 28, no. 1-3, pp. 381-390, 1988.

[4] T. Stathopoulos and Y. S. Zhou, "Numerical simulation of wind-induced pressures on buildings of various geometries," Journal of Wind Engineering and Industrial Aerodynamics, vol. 46-47, pp. 419-430, 1993.

[5] K. Miyashita, J. Katagiri, O. Nakamura et al., "Wind-induced response of high-rise buildings Effects of corner cuts or openings in square buildings," Journal of Wind Engineering and Industrial Aerodynamics, vol. 50, pp. 319-328, 1993.

[6] Q. S. Li, J. Q. Fang, A. P. Jeary, and C. K. Wong, "Full scale measurements of wind effects on tall buildings," Journal of Wind Engineering and Industrial Aerodynamics, vol. 74-76, pp. 741-750, 1998.

[7] M. G. Gomes, A. M. Rodrigues, and P. Mendes, "Experimental and numerical study of wind pressures on irregular-plan shapes," Journal of Wind Engineering and Industrial Aerodynamics, vol. 93, no. 10, pp. 741-756, 2005.

[8] S. Chakrabortya, S. K. Dalui, and A. K. Ahuja, "Experimental and numerical study of surface pressure on '+'plan shape tall building," International Journal of Construction Materials and Structures, vol. 1, pp. 45-48, 2013.

[9] J. A. Amin and A. K. Ahuja, "Effects of side ratio on windinduced pressure distribution on rectangular buildings," Journal of Structures, vol. 2013, Article ID 176739, 12 pages, 2013.

[10] A. K. Dagnew, G. T. Bitsuamalk, and M. R., "Computational evaluation of wind pressures on tall buildings," in Proceedings of 11th American conference on Wind Engineering, San Juan, PR, USA, June 2009.

[11] S. Chakraborty, S. K. Dalui, and A. K. Ahuja, "Wind load on irregular plan shaped tall building-a case study," Wind and Structures, vol. 19, no. 1, pp. 59-73, 2014.

[12] J. Yi and Q. S. Li, "Wind tunnel and full-scale study of wind effects on a super-tall building," Journal of Fluids and Structures, vol. 58, pp. 236-253, 2015.

[13] Y. Li and Q. Li, "Across-wind dynamic loads on L-shaped tall buildings," Wind Structures, vol. 23, no. 5, pp. 385-403, 2016.

[14] B. Bhattacharyya and S. K. Dalui, "Investigation of mean wind pressures on 'E' plan shaped tall building," Wind and Structures, vol. 26, no. 2, pp. 99-114, 2018.

[15] L. Li, B. Wen, and L. Yihua, "Recent efforts for credible CFD simulations in China," Modelling and Simulation in Engineering, vol. 2011, Article ID 861272, 8 pages, 2011.

[16] W. K. Chow, C. L. Chow, and S. S. Li, "Simulating smoke filling in big halls by computational fluid dynamics," Modelling and Simulation in Engineering, vol. 2011, Article ID 781252, 16 pages, 2011. 
[17] A. Mohanta and K. C. Patra, "LES modeling with experimental validation of a compound channel having converging floodplain," Journal of The Institution of Engineers (India): Series A, vol. 99, no. 3, pp. 519-537, 2018.

[18] B. Bhattacharyya and S. K. Dalui, "Along and across wind effects on irregular plan shaped tall building," in Advances in Structural Engineering, Springer, New Delhi, India, 2015.

[19] D. Jana, T. Bhaduri, and S. K. Dalui, "Numerical study of optimization of interference effect on pentagonal plan shaped tall building," Asian Journal of Civil Engineering, vol. 16, no. 8, pp. 1123-1153, 2015.

[20] S. Swaddiwudhipong and M. S. Khan, "Dynamic response of wind-excited building using CFD," Journal of Sound and Vibration, vol. 253, no. 4, pp. 735-754, 2002.

[21] Y. Cheng, F. S. Lien, E. Yee, and R. Sinclair, "A comparison of large eddy simulations with a standard $k-\varepsilon$ Reynolds-averaged Navier-stokes model for the prediction of a fully developed turbulent flow over a matrix of cubes," Journal of Wind Engineering and Industrial Aerodynamics, vol. 91, no. 11, pp. 1301-1328, 2003.

[22] F. Villalpando, M. Reggio, and A. Ilinca, "Assessment of turbulence models for flow simulation around a wind turbine airfoil," Modelling and Simulation in Engineering, vol. 2011, Article ID 714146, 8 pages, 2011.

[23] T. Uchida, T. Maruyama, and Y. Ohya, "New evaluation technique for WTG design wind speed using a CFD-modelbased unsteady flow simulation with wind direction changes," Modelling and Simulation in Engineering, vol. 2011, Article ID 941870, 6 pages, 2011.

[24] J. Franke, C. Hirsch, A. G. Jensen et al., "Recommendations on the use of CFD in Wind engineering," in Proceedings of International conference on Urban Wind Engineering and Building Aerodynamics: COST C14: Impact of wind and storm on City life and Built Environment, Rhode-Saint-Genèse, Belgium, May 2004.

[25] S. Mukherjee, S. Chakraborty, S. K. Dalui, and A. K. Ahuja, "Wind induced pressure on 'Y' plan shape tall building," Wind and Structures, vol. 19, no. 5, pp. 523-540, 2014.

[26] A. H. Gandomi, G. J. Yun, and A. H. Alavi, "An evolutionary approach for modeling of shear strength of RC deep beams," Materials and Structures, vol. 46, no. 12, pp. 2109-2119, 2013.

[27] A. Mohanta, K. Patra, and B. Sahoo, "Anticipate Manning's coefficient in meandering compound channels," Hydrology, vol. 5, no. 3, p. 47, 2018. 


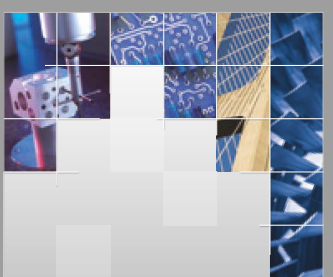

\section{Enfincering}
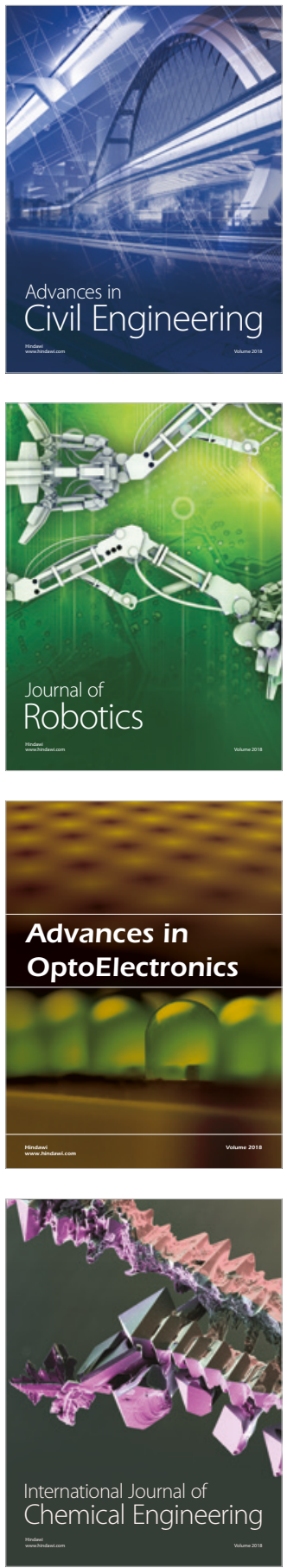

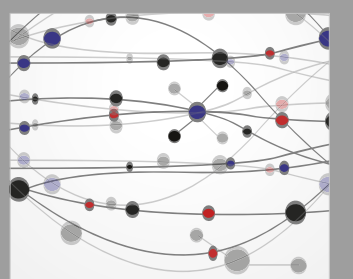

\section{Rotating \\ Machinery}

The Scientific World Journal

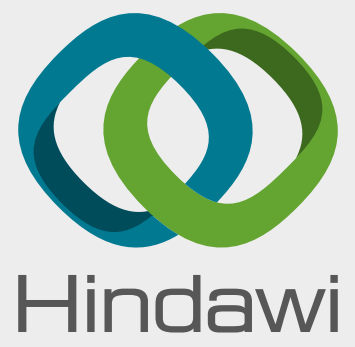

Submit your manuscripts at

www.hindawi.com
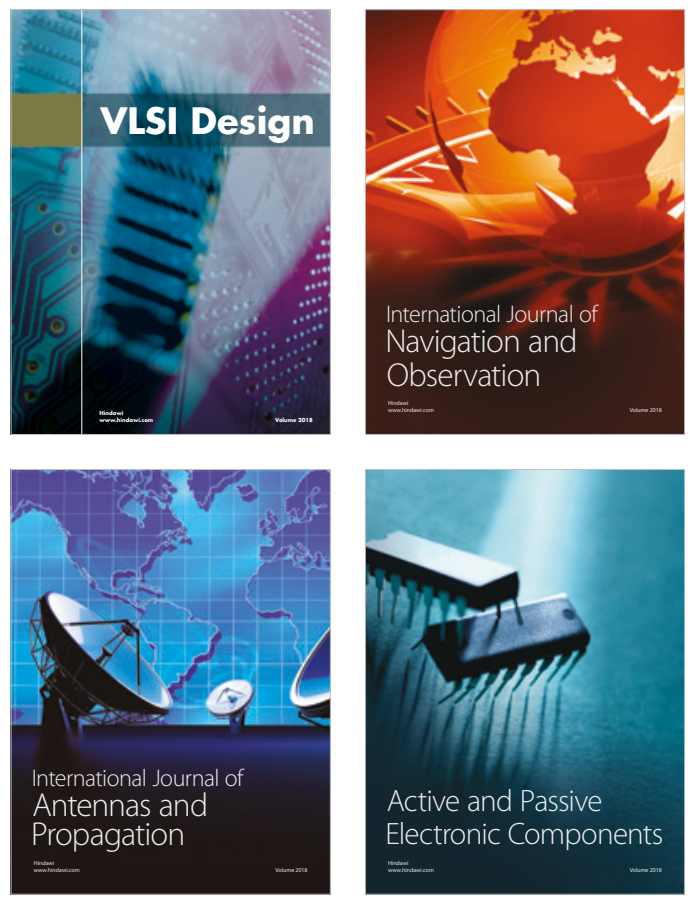
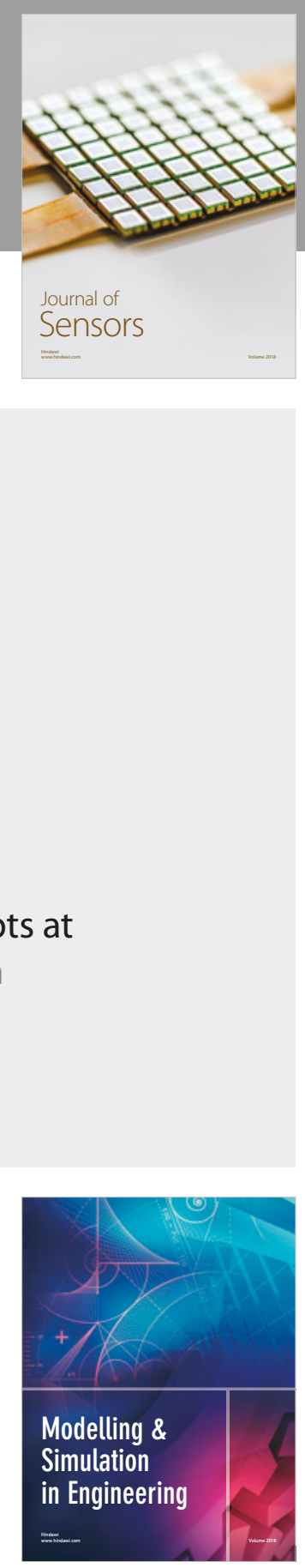

\section{Advances \\ Multimedia}
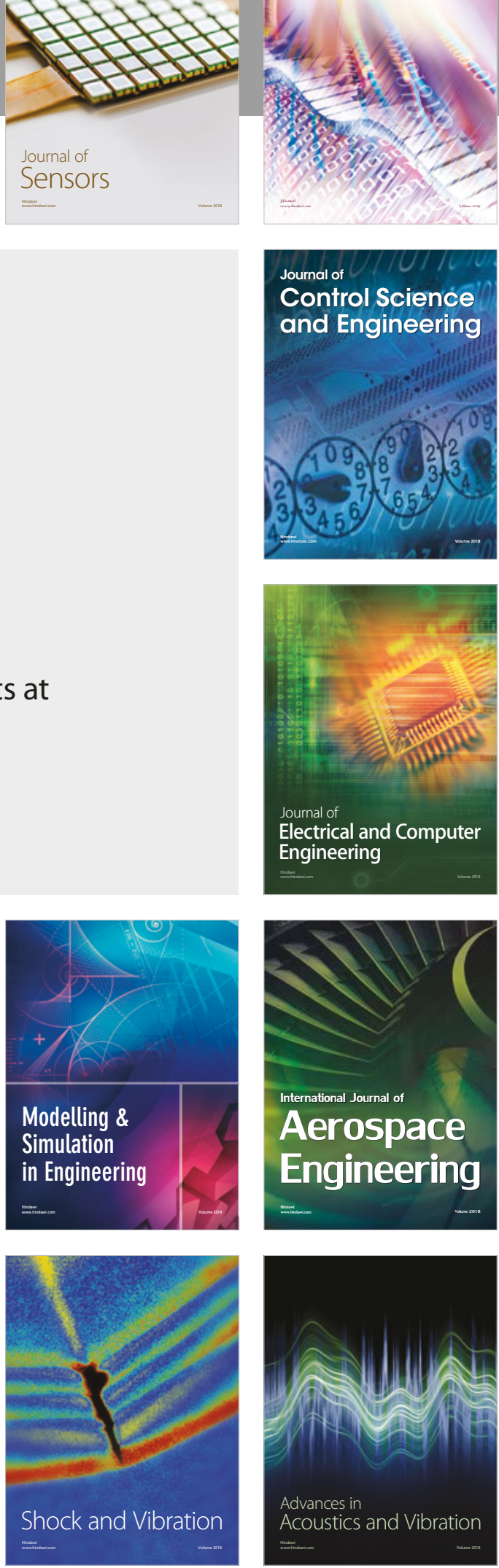